University of Montana

ScholarWorks at University of Montana

3-2018

\title{
Maintaining digital collections with declining resources, fewer staff
}

Wendy Walker

University of Montana - Missoula, wendy.walker@umontana.edu

Teressa M. Keenan

University of Montana - Missoula

Follow this and additional works at: https://scholarworks.umt.edu/ml_pubs

Part of the Library and Information Science Commons

Let us know how access to this document benefits you.

\section{Recommended Citation}

Wendy Walker, Teressa Keenan, (2018) "Maintaining digital collections with declining resources, fewer staff", Digital Library Perspectives, Vol. 34 Issue: 2, pp.91-100, https://doi.org/10.1108/DLP-07-2017-0025

This Article is brought to you for free and open access by the Mansfield Library at ScholarWorks at University of Montana. It has been accepted for inclusion in Mansfield Library Faculty Publications by an authorized administrator of ScholarWorks at University of Montana. For more information, please contact scholarworks@mso.umt.edu. 


\title{
Title: Maintaining Digital Collections with Declining Resources, Fewer Staff
}

\author{
Abstract: \\ Purpose - This paper describes methods for restructuring workflows and efficiently utilizing staff \\ members and volunteers to continue work on multiple, simultaneous digital collections as budgets and \\ resources decline. \\ Design/methodology/approach - Descriptions of one library's varied approaches to several digital \\ collections supported by literature on volunteers in libraries. \\ Findings - In the face of continually declining resources and new, time-sensitive priorities and \\ compliance responsibilities, librarians can continue to maintain digital collections by modifying \\ workflows, utilizing the services of volunteers, and communicating strategically. \\ Practical implications - This paper is relevant to librarians, archivists and others who are looking for \\ ways to justify and capitalize on the use of unconventional personnel in digital collections programs. \\ Originality/value - This paper presents a case of the successful use of volunteers to accomplish digital \\ collections-related tasks in an academic library and provides a communication-based strategy for \\ addressing some of the challenges related to volunteers in academic libraries.
}

Keywords: staffing, digital collections, volunteers, digitization workflows, student workers, communication, accessibility 


\section{Introduction/Background}

The Maureen and Mike Mansfield Library (Mansfield Library) at the University of Montana established a Digital Production Unit and formally began creating collections of digitized content in 2010. The Unit was led by a Digital Projects Librarian and employed one full-time staff member as well as a handful of students. With a sole focus on digital collections, the Librarian, staff member, and students digitized materials, created metadata, and uploaded items to the Library's online digital collections repositories. In 2013, several months after the Digital Projects Librarian had moved on to another institution, a new librarian was hired to lead the Digital Production Unit with the new title Digital Initiatives Librarian.

\section{Model Workflow and Staffing}

The Digital Initiatives Librarian continued to oversee the established workflow for digital collections, which typically began with a project proposal. The Library's Archives and Special Collections Unit as well as entities outside the University proposed several digital collections over the years. The Digital Projects Committee, chaired by the Digital Initiatives Librarian and populated by faculty and staff representing all units within the Library, reviewed and evaluated proposals. The Committee's primary criteria for approval or rejection of a proposal included project scope, project size, preservation and access requirements, consideration of copyright, and required resources.

Once the Committee approved a proposal, the Digital Initiatives Librarian worked with the full-time staff member in the Digital Production Unit to flesh out the project parameters and to distribute the work of scanning and file processing to the Unit's student workers. As digitization progressed, the Digital Initiatives Librarian worked with the Head of Bibliographic Management Services/Metadata Librarian (Head of BMS) to finalize the metadata for the project. BMS staff members then created the metadata for the digitized items. Quality controls at various points throughout this workflow helped to ensure that project parameters were followed and that project stakeholders remained satisfied with the project's progress and products. Depending on the content and the repository selected for access, either BMS staff or the Digital Initiatives Librarian uploaded the collection items for online access. The Digital Initiatives Librarian remained responsible for coordinating each project and for final collection and repository configurations. (Figure 1).

\section{Disruptions to the Model}

An ongoing decline in the University and Library budgets since 2013 has resulted in fewer resources for digital collections. In addition, and partly as a result of this decline, a number of Library staff members have decided to seek employment elsewhere. In summer 2015 the full-time staff member in the Digital Production Unit quit. A few months later, before this position was re-filled, the University president announced layoffs across campus. The Library Dean elected to forfeit vacant positions, including the one from the Digital Production Unit, rather than discharge working library employees. In fall 2015, two staff members voluntarily left their positions in BMS. In fall 2016 another BMS employee retired. Only one of these BMS positions was subsequently refilled, leaving only two of the remaining three BMS staff members to assist, as time permitted, with metadata for digital collections. Figure 2 illustrates the decline in staff over time. The loss of staff members and positions in the Digital Production and BMS Units severely impacted the model digital collections workflow. Digitization and file processing now depended solely on the fluctuating, part-time work of five or six student workers, and the remaining BMS staff members had a lot less time to devote to digital collections metadata. 
Other circumstances also disrupted the model workflow. In spring 2014 the University of Montana signed a Resolution Agreement with the U.S. Department of Education, Office for Civil Rights regarding the accessibility of electronic and information technology (University of Montana and U.S. Department of Education, Office for Civil Rights 2014). The campus-wide scope of the Resolution Agreement compelled the Digital Initiatives Librarian and the Head of BMS to review existing and in-process digital collections, including metadata, for accessibility. The Librarians discovered a number of issues in its digitized text, metadata, and repositories that required remediation and changes in the digital collections workflow.

New, competing priorities within the Library also resulted in fewer resources for digital collections. The librarian position in charge of the Digital Production Unit was filled under the new title of Digital Initiatives Librarian in 2013 as a result of the inclusion of new responsibilities; in addition to leading the Digital Production Unit and overseeing digital collections, the Digital Initiatives Librarian was responsible for selecting, building, and managing a new institutional repository (IR). The IR-related work diverted time away from the oversight of the Digital Production Unit, a shift that was especially pronounced after the departure of the full-time staff member in the Unit and the subsequent loss of that staff member's position altogether.

By early 2015 the Digital Production Unit was working on several large-scale, multi-year projects, one of which required a major change part-way through the digitization process. The Unit's students had digitized about one-third of 105 years' worth of student newspapers from microfilm when the uneven, poor quality of the microfilm became an insurmountable problem. The Digital Initiatives Librarian made the difficult decision to re-digitize the newspapers from extant print copies, which resulted in the loss of several months' work and a slower digitization process but ultimately produced higher-quality, more legible images. While large projects and unexpected changes to them are part and parcel of digital collections work, the occurrence of these projects and this significant setback amidst the changes to staffing levels and the implementation of campus-wide accessibility initiatives placed a heavy toll on the progress of digital collections.

Finally, in early 2016, the Library Dean announced an upcoming, major migration from the Integrated Library System (ILS) to a next-generation Library Resource Management (LRM) platform. This migration was the result of ongoing collaborations between the Mansfield Library and the Montana State University (MSU) Library. Working together the two University Libraries were able to fund a much needed upgrade to their outdated systems, a goal which neither institution's budget would have supported independently. While this collaboration made the migration possible, it also added new challenges which directly impacted digital collections. One of the most significant difficulties was the accelerated timing of the implementation process for the new LRM. Due to the fact that MSU's contract with their ILS provider ended on December 15, 2016, the entire migration process had to be completed in approximately 8 months. The now skeletally-staffed BMS Unit became inundated with cataloging clean-up and data preparation, leaving even less time for digital collections metadata.

\section{Carrying On}

The Digital Production and BMS Units were expected initially to continue to create digital collections even while time and resources for these collections dwindled. While students continued to capture and process digitized images in the Digital Production Unit, the Digital Initiatives Librarian had to work very 
collaboratively and creatively with the Head of BMS in order to find workflow efficiencies, particularly for metadata creation, and to obtain the personnel time needed to address the disruptions to the model workflow. Furthermore, these Librarians worked together to send consistent messages to the rest of the Library about the consequences of declining resources, including fewer staff members and positions, for digital collections. This messaging ultimately laid the groundwork for both the Digital Production Unit and BMS to scale back, but not halt, digital collections activities. The following examples describe their efforts and related outcomes.

\section{- Archival Photographs from the University of Montana}

This digital collection has been ongoing since 2006. The original workflow for the collection started in Archives and Special Collections (ASC), where a full-time staff member selected and digitized photographs and uploaded them to CONTENTdm with basic metadata. As use of this collection increased, researchers as well as the Archivist expressed a desire for more consistent and in-depth metadata for the collection to increase ease of access and discovery.

BMS staff members began enhancing the metadata with LCSH terms, controlled terms for geographic locations, authoritative names for creators and contributors, and enriched descriptions. Over time the general workload in ASC and BMS increased. This increase, combined with the difficulties of editing such a large and diverse collection using the CONTENTdm platform, made this experimental workflow inefficient for all staff members involved.

In summer 2014 the Head of BMS was supervising a library school intern, whom she tasked with establishing a new workflow in order to address the inefficiencies. Upon implementation, the new workflow would need to require less time from the ASC staff member, provide more control over the quality of the metadata by BMS staff, and utilize each Unit's resources more effectively. The intern shadowed and interviewed staff in both ASC and BMS then created and tested three different workflows before choosing the one that is still being used today. (Figure 3). In 2015 BMS staff further refined the workflow by incorporating the use of OpenRefine during the quality control portion of the process. OpenRefine is an open source tool that provides a means of analyzing and cleaning data; transforming data from one format to another; and adding web services and external data (OpenRefine n.d.). The resulting workflow allows each participant in the project to focus on their area of expertise, reduces the time from digitization to online access, and lessens the workload stress for individual staff members.

At about the same time that the intern configured a new workflow for this collection, a family member of one of the BMS staff members, an amateur historian and experienced researcher, became quite interested in researching photographs for which little information was available. He continues to volunteer, providing missing metadata for a number of photographs in this collection, including dates, names of people, locations, buildings, events, and vehicles.

For this project, the intern gained valuable experience while solving a real-world problem. The Library staff members benefited from a redistribution of their workloads and were able to refocus on their primary skillsets. An unexpected volunteer enhances the metadata, a benefit to the Library and to the users of this collection. He reports feeling great satisfaction while conducting historical research (a favorite hobby) and contributing to a greater good (Lankston 
2017). This project continues to grow and remains one of the most used of the Library's digital collections.

- Diaries, Letters and Ledgers from the University of Montana

This digital collection includes a number of handwritten diaries. Digitized handwritten materials remain relatively inaccessible for a number of reasons. Optical character recognition (OCR) software cannot process handwriting, so the diary content is not searchable by anyone, and it is not readable by assistive technologies. Further, handwriting quality varies. Even when readable by sight, poor handwriting can be difficult to read by even the most astute reader.

Transcription of handwritten documents is a time consuming task that requires concentration and great attention to detail. Given increasing workloads and reduced staff resources, neither the Head of BMS nor the Digital Initiatives Librarian wanted the personnel in their Units to undertake this task. While ASC staff typically have more experience working with handwritten materials, they were also facing reduced resources and increased workloads, so reaching out to that Unit for assistance was not a viable solution.

In February 2015, the Head of BMS was approached by an employee consultant with Opportunity Resources, a local organization "dedicated to supporting persons with disabilities" (Opportunity Resources, Inc. n.d.). The employee consultant was seeking a work experience for a disabled veteran. The employee consultant, the veteran, and the Head of BMS met and reviewed the transcription project requirements for this digital collection. Appropriate forms were completed, and the volunteer began work on the project later that month. The Head of BMS arranged for a dual-screen computer workstation for the volunteer, provided initial training for the project, and provided assistance with the technology as needed. A staff member in BMS updated the digital collection by adding the volunteer's completed transcripts to CONTENTdm.

This collaboration proved to be even more successful than anticipated. The volunteer transcribed eight diaries and reviewed and corrected another typed diary's OCR transcription. Additionally, this volunteer contributed specialized knowledge and experience that enhanced the transcripts he produced. Three of the diaries included accounts of the Civil War. Due to his military background, the veteran was able to add notes that defined or spelled out the military jargon and abbreviations in the diaries. His work improved both the accessibility and the searchability of the content in this collection.

\section{- University of Montana News Releases}

This large-scale, multi-year project involves the digitization of over 60 years' worth of University of Montana press releases. When the Digital Projects Committee initially approved this project, it was assumed that BMS staff members would have time to create the relatively minimal metadata needed for this project (titles when needed, release dates) and to upload the items to the IR. However, staff and position reductions and new priorities prevented even this very basic level of metadata and upload from being feasible for remaining BMS staff members.

One of the students from the Digital Production Unit, who digitized and processed files for this collection for two years, graduated in fall 2016. She applied for library school and notified the Digital Initiatives Librarian that she had been admitted and would begin school in fall 2017. 
Although she planned to move two hours away after graduation, the Digital Initiatives Librarian asked her if she would be interested in working as a volunteer, creating metadata for this collection until she started library school. The student agreed. Using the University's cloudbased Box service to work with the collection items, the student prepared metadata for nearly 4,000 press releases. This arrangement provided the student with additional library experience in preparation for graduate school, particularly with digital content, digital collections, and metadata, and helped the Library continue to make progress on a large project that otherwise receives fewer resources than originally planned.

\section{- Natives of Montana Archival Project (NOMAP)}

The Natives of Montana Archival Project (NOMAP) collects primary source documents related to the various tribes of Montana. Over the course of four summers (2009-2012), students from the Native American Studies Department at the University of Montana photographed a total of 65,714 pages from 126 boxes of Bureau of Indian Affairs records (Record Group 75) held at the National Archives in Washington, D.C. (Maureen and Mike Mansfield Library n.d.)

Each digitized box of documents was uploaded to CONTENTdm as a compound object, so the collection includes 126 items (boxes). The resulting structure is difficult to search and navigate, particularly for users who use assistive technologies (Walker \& Keenan 2015). This project needed remediation due to campus-wide accessibility compliance requirements. In addition, BMS staff members had long wanted to correct errors and omissions in the metadata. When a BMS staff member announced her retirement in 2016, the Head of BMS and the Digital Initiatives Librarian worked with her to arrange weekly volunteer hours that would provide her with time to re-create this collection in order to make it more accessible, navigable, and searchable.

The ex-staff-volunteer model works beautifully as the individual already understands the Library's processes, programs, and technologies. In this case, in particular, the ex-staff member worked on the original digital collection; she possesses in-depth understanding of the content, the specific collection metadata, and the reasons that her volunteer work will improve access to the collection.

\section{- Internal Digital Production Unit changes}

In addition to adjustments to collection-specific workflows and the utilization of volunteers' services, the Digital Initiatives Librarian redistributed the work within the Digital Production Unit. The full-time staff member had originally organized the work in the Unit in such a way that students could work on any step in the digitization process for any project during any shift. This approach had its advantages. It required each student to understand each step in the process and permitted them some freedom in terms of their choice of task during their shifts. Tracking logs for each project generally prevented this system from becoming too unwieldy; however, when students forgot to complete the tracking log, mistakes and duplicate work occurred. Furthermore, students never felt particularly invested in any one collection and were more likely to overlook errors that can occur without a "big picture" understanding of a single project. 
After the departure of the Unit's full-time staff member, the Digital Initiatives Librarian organized the student workers in the Unit into two-person project teams. This reorganization made it easier to track the progress of each project, and students began spotting issues related to their projects because they now had a more holistic understanding of the project to which they had been assigned.

- Communication strategy

Importantly, the Digital Initiatives Librarian and Head of BMS strategically seized several opportunities to communicate to others in the Library the ongoing impact of budget cuts and the loss of staff members and positions. At faculty meetings, committee meetings, and in other discussions with colleagues, the Digital Initiatives Librarian and Head of BMS delivered planned, coordinated messages that clearly articulated that while volunteers and other workflow modifications helped achieve some digital collections tasks and efficiencies, volunteers do not supplant employees, and both Digital Production and BMS employees were necessarily producing less in terms of digital collections.

In early 2016, as a result of their strategic communications, the Digital Initiatives Librarian successfully made the case to the Library to temporarily suspend Digital Projects Committee meetings and to stop soliciting new digital collections proposals. The Digital Initiatives Librarian would re-evaluate resources and the Library's capacity to undertake new digital collections as in-process collections neared completion, but in the meantime, it simply seemed irresponsible to consider new project proposals. The students in the Digital Production Unit were working on three large-scale projects; staff and resources continued to decline; and students' changing schedules and external commitments made productivity unpredictable. Library faculty and staff accepted the suspension without hesitation, confirming their understanding that sometimes it is necessary to do less with less.

\section{Modified Workflows and Volunteers: Benefits and Challenges}

While it is usually still possible to do something, and there are benefits to doing so, there are also several challenges to finding alternatives to the model workflow and the standard staffing solutions. There is a body of research wherein authors specifically explicate the benefits and challenges of volunteers in academic libraries (Smallwood \& Sanborn 2016; Throgmorton 2016; Barlett 2013; Crumpton 2013; Forrest 2012; Hoy 2011; Schobernd, Tucker \& Wetzel 2009). Here is brief summary of many of the points that are described in the literature and that also held true at the Mansfield Library.

Benefits:

- Continue to make progress on current digital collections and conduct important maintenance on existing ones.

- Discover unexpected efficiencies after reconsidering and redesigning a workflow.

- Redistributing project tasks can allow individual staff members to focus on their existing strengths rather than spend valuable time learning something new.

- Volunteers and interns obtain the interesting work and valuable experience that they want and/or need. 
- Utilizing the services of volunteers provides the Library with yet another opportunity to engage in community outreach.

\section{Challenges:}

- Volunteers, like students, have other priorities and usually do not work full time, so while progress continues, it may be slow.

- Utilizing the services of volunteers and interns may require significant training time. Written instructions help, especially in the long term, but it takes time to write them, so there is a shortterm cost.

- Over time, the ability to make progress on digital collections with volunteers can contribute to a perception that digitization and digital collections are ad-hoc activities that may not require permanent staff or sustained funding.

- The use of volunteers can incite the perception "that volunteers are viable replacements for librarians and staff"' (Bartlett 2013).

These last two points are the most difficult to address, but they can be effectively addressed through consistent, clear messaging. The Digital Initiatives Librarian and the Head of BMS spent time crafting messages that articulated the successes of the volunteers but that also highlighted the digital collections activities and goals that could not be achieved without regular staffing and sustained funding.

\section{Conclusions}

A series of circumstances over the last several years contributed to an ever-shifting landscape wherein the model digital collections workflow became less feasible over time. Rather than halt operations in the Digital Production Unit altogether - which was an (unfavorable) option - the Digital Initiatives Librarian worked with the Head of BMS to find alternative solutions for making progress on in-process digital collections, for enhancing and maintaining existing ones, and for realistically managing a digital collections program given resource and personnel-related constraints.

For both the Digital Initiatives Librarian and the Head of BMS, the work of strategically navigating these complex conditions reinforced the importance of remaining both adaptable and open to circumstantial opportunities. Librarians often contend with new, additional responsibilities; integrating new standards; changing priorities; and even budget cuts and the loss of paid personnel (especially in recent years), but in this case, the mostly unforeseeable loss of staff members and the inability to replace them; the force and timing behind the new campus-wide accessibility requirements (a government-enforced Resolution Agreement with specific, relatively short deadlines for compliance); the rapid timing involved in the ILS migration; and the severity of the budget cuts tested the Librarians' mettle.

The Librarians had to think flexibly about how digital collections could be organized and completed differently due to changing circumstances. Without a formal, library-specific volunteer program in place, the Librarians capitalized on personal networks and providential circumstances to recruit volunteers. Finally, they strategically and repeatedly seized opportunities to communicate the consequences of declining resources; to make a case for scaling back operations; and to reiterate the value and importance of paid library staff members in terms of sustaining and growing digital collections. 


\section{References}

Barlett, J. (2013), "Handle with care: Benefits and drawbacks of volunteers in the library", Library Leadership \& Management, Vol. 27 No. 3, pp. 1-4.

Crumpton, M.A. (2013), "Having a student volunteer program is a win-win", The Bottom Line: Managing Library Finances, Vol. 26 Iss. 2, pp. 55-58.

Forrest, M. (2012), "Student volunteers in academic libraries", New Review of Academic Librarianship, Vol. 18 No. 1, pp. 1-6.

Hoy, M. (2011), "Building pathways to working with collections: Can internships and student work experience help?" Australian Academic \& Research Libraries, Vol. 42 No. 1, pp. 29-42.

Maureen and Mike Mansfield Library (n.d.), "Natives of Montana Archival Project", available at: http://www.lib.umt.edu/research-find/digital-collections/native-montana-archival-project/default.php [accessed 24 July 2017].

OpenRefine (n.d.), “Welcome!”, available at: http://www.openrefine.org [accessed August 7, 2017].

Opportunity Resources, Inc. (n.d.), "About Us”, available at: https://www.orimt.org/about-us.html [accessed July 25, 2017].

Schobernd, E., Tucker, T., and Wetzel, S. (2009), "Closing the gap: Use of student volunteers in an academic library", Technical Services Quarterly, Vol. 26 No. 3, pp. 194-198.

Smallwood, C. and Sanborn, L. (eds.) (2016), Library Volunteers Welcome! McFarland \& Company, Jefferson, NC.

Throgmorton, K. (2016), "Recruiting and Retaining Volunteers", American Libraries Magazine,

University of Montana and U.S. Department of Education, Office for Civil Rights (2014), "Resolution Agreement", available at:

http://www.umt.edu/accessibility/docs/AgreementResolution March 7 2014.pdf [accessed 25 July 2017].

Walker, W. and Keenan, T.K. (2015), "Do you hear what I see? Assessing accessibility of Digital Commons and CONTENTdm", Journal of Electronic Resources Librarianship, Vol. 27 No. 2, pp. 69-87. 